\title{
COVID-19: MOVING TOWARDS THE NEW NORMAL
}

\author{
DS Briggs AM
}

Since the last issue when we first spoke of the impact of Covid-19 we continue to be focused on addressing the challenges this virus has on health systems, nation states, communities, and people. The approach of countries and health systems has been variable as has the political interventions and interpretations of policy with some unfortunately placing parochial populism ahead of evidence and common sense.

Fortunately, political leaders and health policy makings are now examining what lessons can be learned and how we might develop a more balanced evidence based logical and compassionate approach to both community need and collective interests. One example of this is the work of Lieu and colleagues from the Institute for Health Policy and Systems Research that are providing through YouTube across country dialogue about Asia's post-pandemic health care. These multiple presentations are available at https://www.ihpsr.org.hk/. At the same time, the South China Morning Post traversed the differences between largely Asian countries relative success with the virus compared with western countries that includes commentary from a number of health professional and academic colleagues in a range of countries. [1]

Han, Tan and colleagues [ 2 ] have turned our attention to the lessons learnt across nine high income countries, five from the Asia Pacific region, Hong Kong (SAR), Japan, New Zealand, Singapore and South Korea as well as four European countries of Germany, Norway, Spain and the United Kingdom (UK). They provide a comparative analysis of lessons learned from the experiences of those countries.

These authors [2, p.1525] used an adaptive framework to present the analysis utilizing six measures of overall strategy, knowledge of infectious status, community engagement, public health capacity, health system capacity and measures for border control. They suggest that communities be fully engaged and empowered in the policy and process around decision making that affects their protection from the virus and the effect of the crisis. They go on to suggest that advice needs to be 'consistent and credible' and that 'principles of coproduction' of policy should be used. [ 2, p.1527] Mention was made about differing measures of what constitutes social distancing between countries and about policies that direct the wearing of masks.

The authors state that 'with few exceptions, political leaders have struggled to secure public trust and thus support for continued lifestyle changes.' [ 2 p.1529] The authors go on to cite other research that suggests that countries with female leaders 'have done better at securing public confidence and adherence to new measures than countries with male leaders'.[2, p.1529, 3] While many countries were not prepared to cope with the rapid pace of the spread of the virus some countries such as South Korea and Hong Kong (SAR) used to varying degrees, electronic health records, credit card transaction data, mobile phone positioning systems, close circuit television and police supercomputers to name some of the technology. [ 2 p.1530]

In conclusion Han, Tan et al suggest that we are not returning to normal but to a new normal. They suggest that all countries need a plan to move forward based primarily on epidemiological considerations. Secondly, we need systems to 'robustly monitor' the infection status before restrictions are eased. Measures to reduce transmission will be needed for some time and every country needs an 'effective find, test, trace, isolate, and support system'. [ 2, p.1532] There is much to be read in this Lancet article and I would encourage readers and colleagues to read the article content and reflect on the relevance to what has occurred in your health system. 
The authors cited above raise the issue of coproducing policy and process as a better way to gain implementation and acceptance and credibility as a means for health systems and government to move forward. Felipe and colleagues [4] pre Covid published a perspective on coproduction of knowledge, values, and social relations in health care. They describe co-production 'as a way of working together to improve health and of creating user led, people - centred health care services.' [ 4 p.1, 5] Felipe and colleagues see co-production as a space that brings together differing values and social relations that produces 'new interactions and forms of knowledge' providing more meaningful ways of 'shaping and taking part in healthcare'. [ 4 p.2] This gives us an opportunity to both codify what we did and did not do in addressing Covid-19 and designing a more inclusive and considered way of determining how we address pandemics in the 'new normal'.

Langley and colleagues [ 6 ] describe 'collective making' as a means to contribute to participatory design in the cocreation of knowledge in healthcare and blurring the boundaries between knowledge producer and knowledge user to the extent that 'dynamic and adaptive community partnerships are nurtured and developed'. These authors suggest that today's challenges require transdisciplinary approaches that blend skills, knowledge, and experience. A truism in respect to the Covid-19 challenges. [6, p.585]

Sandholt and colleagues [ 7 ] suggest that health systems need to adjust services to 'the needs of complex, ageing populations and again the Covid experience has described the vulnerability of aged care residents in care homes and the tensions of appropriately meeting the acute health care needs between the acute and aged care sectors. They propose 'human-centred design as a method to engage older adults and key professionals in innovation processes.' [ 7, p.4551] They describe a model based on inspiration, ideation and implementation and the challenges as recruitment, time, and resources. These authors propose that human centred design methods place the 'perspectives of older adults at the centre and recognizing the value of interdisciplinary work.' [ 7, p.4550]

The USA based Commonwealth Fund has just published the report of a task force on health care delivery system reform [ 8 ] that looks at the impact of Covid-19 overlayed over what they describe as the existing disparities of the USA health system. The task force was designed to focus on a vision of equitable and affordable healthcare for all and had goals of improving quality, advancing equity, and increasing affordability. The task force suggested six policy imperatives to achieve its goals. Imperatives are described as increasing delivery system preparedness for health disasters, greater accountability for healthcare quality, equity and cost, the strengthening of the primary healthcare system, supporting the empowerment and engagement of people, families, and communities together with a reduction in administrative burden and an encouragement of a balance of regulatory and competitive approaches to promote a high-performing health system. Similar outcomes to that proposed by Han, Tan, and colleagues in differing health care systems. [2]

Like the USA above, stating an emphasis on PHC, China has substantially increased investment in PHC, partly responding to emerging infectious disease challenges. XiLi [9] and colleagues suggest a number of strategies for health service improvement. They are supportive of other authors cited in this editorial and make a significant point in suggesting that:

The primary health-care system should increasingly be configured to be a learning platform for knowledge generation and utilisation, which is built on digital data and innovative technologies, particularly for staff training, decision support, and quality control. [9, p.1802]

This Journal would be interested in the views of colleagues of 'lessons learned' from the Covid-19 experience and, more importantly how we progress the challenge made by $\mathrm{Xi}$ and colleagues [ 9 ] above,

\section{DS Briggs AM \\ Editor in Chief}

\section{References}

1. Power J. (2020) Coronavirus: why are Western countries like the US and Britain still not learning from Asia's success? South China Morning Post. Available at https://www.scmp.com/weekasia/economics/article/31 10754/coronavirus-whyare-western-countries-us-and-britain-stillnot?utm_source=Facebook\&utm_medium=share widget\&utm_campaign=31 10754\&fbclid=IWAR 15 
HRwUAazk6ydGqVsqmUed8LmAy7sOud0z8HcAn aoaWEHr6PFXHQkaJHs.

2. Emeline Han*, Melisa Mei Jin Tan*, Eva Turk, Devi Sridhar, Gabriel M Leung, Kenji Shibuya, Nima Asgari, Juhwan Oh, Alberto L GarcíaBasteiro, Johanna Hanefeld, Alex R Cook, Li Yang Hsu, Yik Ying Teo, David Heymann, Helen Clark, Martin McKee, Helena Legido-Quigley Lessons learnt from easing COVID-19 restrictions: an analysis of countries and regions in Asia Pacific and Europe Lancet 2020; 396: 1525-34 Published Online September 24, 2020 https://doi.org/10.1016/ S01406736(20)32007-9.

3. Coscieme L, Fioramonti L, Mortensen LF, et al. Women in power: female leadership and public health outcomes during the COVID-19 pandemic. medRxiv 2020; published online July 16.https://doi.org/10.1101/2020.07.13.20152397 (preprint).

4. Filipe A, Renedo A, Marston C (2017) Thecoproduction of what? Knowledge, values, and social relations in health care. PLoS Biol 15(5): e2001403. https://doi.org/10.1371/journal. pbio. 2001403

5. Kickbusch I, Gleicher D. Governance for Health in the 21st Century. Copenhagen: World Health Organization (WHO) Regional Office for Europe; 2012

6. Langley, J. Wolstenholme, D. Cooke, J. 'Collective making' as knowledge mobilization: the contribution of participatory design in the cocreation of knowledge in healthcare. BMC Health Services Research (2018) 18:585 https://doi.org/10.1186/s12913-018-3397-y.

7. Sandholdt, C.T. Cunningham, J. Westendorp, RGJ. Kristiansen, M. (2020). Towards Inclusive Healthcare Delivery: Potentials and Challenges of HumanCentred Design in Health Innovation Processes to Increase Healthy Aging. Int. J. Environ. Res. Public Health 2020, 17, 4551; doi:10.3390/ijerph17124551 www.mdpi.com/journal/ijerph.

8. The Commonwealth Fund. (2020) Commonwealth Fund Task Force on Payment and Delivery System Reform Health Care Delivery System Reform: Six Policy Imperatives. November 2020. Available from https://www.commonwealthfund.org/publication s/fund-reports/2020/nov/commonwealth-fundtask-force-payment-and-delivery-system-reform
9. Xi Li*, Harlan M Krumholz*, Winnie Yip*, Kar Keung Cheng, Jan De Maeseneer, Qingyue Meng, Elias Mossialos, Chuang Li, Jiapeng Lu, Meng Su, Qiuli Zhang, Dong Roman XU, Liming Li, Sharon-Lise T Normand, Richard Peto, Jing Li, Zengwu Wang, Hongbing Yan, Runlin Gao, Somsak Chunharas, Xin Gao, Raniero Guerra, Huijie Ji, Yang Ke, Zhigang Pan, Xianping Wu, Shuiyuan Xiao, Xinying Xie, Yujuan Zhang, Jun Zhu, Shanzhu Zhu, Shengshou $\mathrm{Hu}$ (2020). Quality of primary health care in China: challenges and recommendations. Lancet 2020; 395: 1802-12. www.thelancet.com Vol 395 June 6, 2020. 